\title{
ENSINO DE OPERAÇÕES DE FRAÇÕES PARA ESTUDANTES CEGOS: UMA POSSIBILIDADE DE ADAPTAÇÃO CURRICULAR
}

\author{
TEACHING FRACTION OPERATIONS TO BLIND STUDENTS: A \\ POSSIBILITY OF CURRICULAR ADAPTATION
}

\author{
Gilbson José Velasco Souza Filho' \\ Regiane da Silva Barbosa²
}

\begin{abstract}
RESUMO: Na perspectiva da inclusão escolar a educação é direito de todos, e para garantir esse direito é preciso que a escola realize modificações para atender a diversidade de estudantes, e dentre estas está prevista a adaptação curricular, que consiste em diversificar a maneira de ensinar de acordo com as especificidades dos estudantes, ou seja, oferecer atividades que possibilitem aprendizagem de todos os conteúdos e conhecimentos previstos para a educação básica. Considerando a relevância da matemática no processo de ensino e aprendizagem e o atual cenário de inclusão escolar surgiu a inquietação: Como ensinar fração para estudantes cegos? E, a partir das interações e reflexões decorrentes da participação em um curso de extensão sobre o tema inclusão escolar desenvolvemos este relato de experiência que tem como objetivo descrever uma possibilidade de adaptação curricular para ensino de operações com frações para estudantes com cegueira. A adaptação curricular descrita foi desenvolvida considerando as características e especificidades de aprendizagem de pessoas com cegueira e do ensino de matemática de maneira contextualizada para desafiar e motivar estudantes a aprender por meio de situações problemas. A sequência de atividades descrita para o ensino de frações para pessoas cegas foi desenvolvida com recursos de baixo custo, demonstrando que adaptação curricular é possível, mas requer troca de informações, ideias e experiencias entre professores e profissionais que atuam na educação.
\end{abstract}

PALAVRAS-CHAVE: Adaptação Curricular. Matemática. Deficiência visual.

\begin{abstract}
From the perspective of school inclusion, education is a right for everyone, and to guarantee this right, the school needs to make changes to carter for the diversity of students, and among these, curricular adaptation is foreseen, which consists of diversifying the way of teaching according to the specifics of the students, in other words, offer activities that enable learning of all the content and knowledge provided for basic education. Considering the relevance of mathematics in the teaching and learning process and the current scenario of school inclusion, the question emerged: How to teach fraction to blind students? From the interactions and reflections that emerged from the participation in an extension course on the theme of school inclusion, we developed this experience report that aims to describe a possibility of curricular adaptation for teaching operations with fractions for students with blindness. The curricular adaptation described was developed considering the characteristics and specificities of learning for people with blindness and of teaching mathematics in a contextualized way to challenge and motivate students to learn through problem situations. The sequence of activities described for teaching fractions to blind people was developed with low-cost resources, demonstrating that curricular adaptation is possible, but requires the exchange of information, ideas and experiences between teachers and professionals working in education.
\end{abstract}

KEYWORDS: Curricular Adaptation. Math. Visual Impairment.

\footnotetext{
1 Universidade Federal da Bahia, Brasil. E-mail: meuprofessordeexatas@gmail.com

iD https://orcid.org/0000-0001-7875-9525

2 Universidade Federal da Bahia, Brasil. E-mail: regiane.barbosa@ufba.br

(D) https://orcid.org/0000-0002-0305-902X

- Informações completas da obra no final do artigo
} 


\section{Introdução}

O presente texto traz um relato de experiência a partir de uma vivência em uma atividade de extensão denominada "Encontros Formativos em Inclusão Escolar e Educação Especial: reflexões e possibilidades práticas", na qual professores de educação básica e graduandos em Pedagogia e cursos de Licenciatura estudam temas da área de educação inclusiva, compartilham ideias, reflexões, práticas, e produzem recursos e materiais adaptados para ensino de estudantes Público Alvo da Educação Especial (PAEE). A prática descrita foi realizada no primeiro semestre de 2021, na elaboração de uma adaptação curricular para ensino de matemática para estudantes com deficiência visual.

De acordo com a legislação vigente (Lei de Diretrizes e Bases da Educação Nacional no 9394 de 1996, Política Nacional de Educação Especial na Perspectiva da Educação Inclusiva de 2008, Lei Brasileira de Inclusão de 2015) a educação é direito de todos, e as escolas de todo país devem adotar a perspectiva da educação inclusiva, ou seja, garantir a todos acesso, permanência e aprendizagem, independentemente das diferenças de cada um, sejam estas de origem social, cultural, étnica, econômica, ou decorrente de deficiência. A exclusão de pessoas com deficiência prevaleceu por muito tempo, quando estas eram excluídas da sociedade e a educação acontecia em espaços segregados, nas instituições especializadas, negando a essas pessoas o acesso aos conhecimentos historicamente produzidos, sem perspectivas de formação para atuar em sociedade e ou no mercado de trabalho (JANUZZI, 2004; MAZZOTTA, 2005).

Atualmente, na perspectiva inclusiva a educação deve ser oferecida na escola, a qual deve se preparar para atender as necessidades de todos os estudantes, oferecendo:

[...] condições de acesso aos espaços, aos recursos pedagógicos e à comunicação que favoreçam a promoção da aprendizagem e a valorização das diferenças, de forma a atender as necessidades educacionais de todos os estudantes (BRASIL, 2008, s/p).

$E$, atendimento educacional especializado para estudantes PAEE, que contempla estudantes com Deficiência, Transtorno do Espectro Autista e Altas Habilidades/Superdotação.

Para atender as necessidades e especificidades de todos os estudantes, inclusive de estudantes PAEE, é preciso que a escola realize mudanças na organização da rotina e 
do processo de ensino e aprendizagem, o que requer conforme Art. 28, Inciso V, da Lei Brasileira de Inclusão da Pessoa com Deficiência:

[...] adoção de medidas individualizadas e coletivas em ambientes que maximizem o desenvolvimento acadêmico e social dos estudantes com deficiência, favorecendo o acesso, a permanência, a participação e a aprendizagem em instituições de ensino (BRASIL, 2015, s/p).

E, uma das possibilidades está na adaptação curricular que consiste em "uma das estratégias da educação inclusiva que procura contribuir para a inclusão daqueles que apresentam dificuldades durante o processo de ensino e aprendizagem" (LOPES, 2017, p.10).

É importante frisar que adaptação não consiste em desenvolver ou criar um novo currículo, específico para o estudante PAEE, pois o currículo é o mesmo para todos, organizado de acordo com o ano escolar e previsto na Base Nacional Comum Curricular (BNCC).

A BNCC é a referência nacional para a formulação dos currículos dos sistemas e das redes escolares, logo nela constam todos os conteúdos/conhecimentos que devem ser desenvolvidos com os estudantes ao longo das etapas e modalidades da Educação Básica. O próprio documento enfatiza que: "para além da garantia de acesso e permanência na escola, é necessário que sistemas, redes e escolas garantam um patamar comum de aprendizagens a todos os estudantes, tarefa para a qual a BNCC é instrumento fundamental" (BRASIL, 2018, p.8).

Para organizar a aprendizagem desenvolvida na Educação Básica o referido documento organiza o Ensino Fundamental em cinco áreas do conhecimento: Linguagens, Matemática, Ciências da Natureza, Ciências Humanas e Ensino Religioso. Neste texto o foco está em Matemática que visa desenvolver:

[...] as competências e habilidades de raciocinar, representar, comunicar e argumentar matematicamente, de modo a favorecer o estabelecimento de conjecturas, a formulação e a resolução de problemas em uma variedade de contextos, utilizando conceitos, procedimentos, fatos e ferramentas matemáticas (BRASIL, 2018, p. 264).

Considerando tais competências pontuadas na educação básica, pensamos em uma adaptação para ensinar um dos conteúdos previstos para o sexto ano do ensino fundamental, primeiro ano da educação básica em que é possível a atuação docente do 
professor licenciado em matemática. No sexto ano, na unidade temática Números está previsto o ensino do conteúdo "Frações: significados (parte/todo, quociente), equivalência, comparação, adição e subtração; cálculo da fração de um número natural; adição e subtração de frações" (BRASIL, 2018, p.298).

Portanto, a BNCC determina que o estudo do objeto do conhecimento matemático das frações seja feito em seus diversos significados: como a parte de inteiros, ou como resultado da divisão, ou na forma de razão. E, como os números, na forma fracionária, são pertencentes ao conjunto dos racionais é importante o estudo da reta numérica dos racionais, pois, o intuito dessa proposta de adaptação curricular de conteúdo previsto na BNCC é a confecção de materiais concretos que permitam o acesso dos estudantes cegos a esse conhecimento, permitindo a construção das habilidades matemáticas dispostas na BNCC, como comparar e ordenar frações associadas às ideias de partes de inteiros e o domínio das operações, mas sempre utilizando a estratégia de resolução de situações problemas de uso cotidiano das frações.

Segundo Nunes e Bryant (2008), as frações são úteis principalmente para representar algo que não conseguimos apresentar através dos números naturais. Pois, não podemos usar números naturais quando a medida que queremos representar numericamente é menor do que a unidade usada para contagem, por exemplo, José quer comprar a granel meio quilo de arroz, ou quando se quer representar a razão entre duas quantidades, por exemplo, a razão entre os números de meninas e meninos de uma turma é de dois terços.

Considerando a importância desse conhecimento na educação básica e na aplicação na vida em sociedade, o atual cenário de educação inclusiva e o direito de todos aprenderem os conteúdos descritos, uma vez que não basta garantir esse direito oferecendo somente acesso dos estudantes a escola, ou seja, a matrícula, é preciso garantir a permanência, e para isso é necessário oferecer aos estudantes oportunidades de aprendizagem, para que progridam nas etapas de ensino, o presente relato decorre da seguinte inquietação: Como ensinar fração para estudantes cegos?

A pessoa com deficiência visual (DV) faz parte do PAEE, sendo assim tem direito de estar na escola e de aprender os conteúdos previstos para o ano escolar em que está matriculada, dentre eles, fração. 


\section{ENSIN@UFMS 2021}

ISSN 2525-7056

A deficiência visual se divide em dois grupos com características e necessidades diferentes: pessoas com baixa visão e pessoas com cegueira. Compreende-se que: pessoas com baixa visão são aquelas que apresentam "[...] desde condições de indicar projeção de luz até o grau em que a redução da acuidade visual interfere ou limita seu desempenho". Nesses casos o processo educativo deve ocorrer por meios visuais aliado ao uso de recursos específicos. Pessoas cegas são aquelas que apresentam "[...] desde ausência total de visão até a perda da projeção de luz". E, para estas pessoas o processo de aprendizagem deve considerar os sentidos remanescentes (tato, audição, olfato, paladar), utilizando o Sistema Braille, como principal meio de comunicação escrita (BRASIL, 2001, p. 15).

O ensino de matemática para pessoas com DV é um desafio, pois ultrapassa a apresentação oral de conteúdo, sendo fundamental incentivar o uso dos sentidos remanescentes para que possam adquirir conhecimentos matemáticos (MOLLOSSI, 2013).

Ao discorrer sobre este tema Uber (2009) enfatiza que os estudantes com DV precisam "sentir" para poder fazer suas abstrações, uma vez que o material manipulado é um dos possíveis meios de acesso ao conhecimento das coisas que os cercam, por isso o presente relato de experiencia tem como objetivo: descrever uma possibilidade de adaptação curricular para o ensino de operações com frações para estudantes com cegueira.

\section{Adaptação Curricular desenvolvida a partir de atividade de extensão}

A atividade de extensão "Encontros Formativos em Inclusão Escolar e Educação Especial: reflexões e possibilidades práticas" aconteceu quinzenalmente de maneira virtual devido ao isolamento social decorrente da Pandemia do Covid-19 e contou com 12 participantes, entre professores da rede municipal de educação de Salvador, estudantes de Pedagogia e de cursos de licenciatura da UFBA. As atividades foram organizadas em momentos síncronos via plataforma virtual (encontros virtuais para troca de informações, ideias, e reflexões sobre temas da área de educação especial e inclusiva) e momentos assíncronos (leitura de textos e desenvolvimento de atividades e de recursos de adaptação curricular).

Nos encontros síncronos discutimos sobre inclusão escolar, ensino e aprendizagem de estudantes PAEE, adaptação curricular, recursos e tecnologia assistiva. E, a partir do 
interesse, formação e área de atuação, cada integrante do grupo escolheu um público alvo e desenvolveu uma possibilidade de adaptação curricular, ou seja, pensou em uma atividade e ou recurso que poderiam ser utilizados no processo de ensino e aprendizagem. As atividades e ou recursos de adaptação curricular foram desenvolvidas considerando as leituras e discussões realizadas nos encontros e sob orientação da professora coordenadora do projeto, e coautora deste relato.

A dinâmica para elaboração das atividades e recursos de adaptação curricular descritos neste relato de experiência foi: escolha do tema (ensino de fração para pessoas com cegueira); apresentação da ideia aos membros do grupo e à professora coordenadora do projeto; escuta das ideias e dicas sobre as possibilidades e recursos a serem utilizados considerando as necessidades e especificidades de estudantes com cegueira; orientação individual com a professora coordenadora do projeto para elaboração dos recursos manipuláveis; produção dos recursos e elaboração das atividades que poderiam contribuir com a aquisição do conhecimento de fração; apresentação dos recursos e atividades desenvolvidos aos integrantes do grupo e à professora coordenadora do projeto para apreciação; escuta de dicas e possibilidades de melhoria dos recursos visando sua utilização e contribuição tanto para estudantes cegos, quanto para estudantes videntes; adequação dos recursos produzidos e reformulação das atividades a partir da escuta e apreciação dos colegas integrantes do grupo e da professora coordenadora. Sendo assim, o autor e coautora deste relato de experiencia foram, respectivamente, participante e ministrante do projeto de extensão mencionado no decorrer do texto.

Considerando o desafio de ensinar matemática para estudantes cegos e a necessidade de divulgar conhecimento sobre o tema para respaldar práticas docentes relatamos a possibilidade de adaptação curricular desenvolvida na referida atividade de extensão.

Para embasar a adaptação curricular descrita neste relato utilizamos como referência: para o processo de ensino e aprendizagem de matemática e frações: BNCC (2018), Scruggs; Mastropieri; Berkeley; Graetz (2010) e Bertoni (2008) e Lupinacci; Botin (2004); para o ensino de matemática para pessoas com DV Mollossi (2013), Saracho (2020), Uber (2009), Schoenfeld (1992). 


\section{ENSIN@UFMS 2021}

ISSN 2525-7056

\section{Ensino de fração para estudantes cegos: adaptando atividades}

Bertoni (2008) em seus estudos sobre o processo do ensino e construção do conhecimento sobre Número Fracionário, destaca a utilização de figuras e materiais concretos junto com as práticas que estimulam o aprendizado das frações numéricas, onde:

As primeiras propostas apoiavam-se em materiais manipulativos e figuras geométricas, que passaram depois a objetos do contexto social e, finalmente, a situações do cotidiano que evidenciavam a necessidade da emergência desses novos números (BERTONI, 2008, p. 214).

Contudo, para os estudante com DV não é possível o ensino de frações desenhando e escrevendo no quadro , pois para o aprendizado do estudante cego é preciso trazer um modelo concreto e manipulável, com o intuito de estimular os sentidos remanescentes, pois a manipulação do material para o ensino da matemática ajuda a esse público a aprender vários conceitos matemáticos, incluindo: adição e subtração, operações com números inteiros e equivalentes de fração (SCRUGGS; MASTROPIERI; BERKELEY; GRAETZ, 2010).

A manipulação do material também oferece às pessoas com deficiência visual experiências concretas para ajudá-las a compreender seu ambiente e aprender conceitos paralelos aos de seus colegas videntes no ambiente da sala de aula (SARACHO, 2020). E para introduzir o conceito de fração utilizamos uma circunferência para representar o inteiro em dupla face: uma em EVA na cor verde e a outra em papelão, com as bordas contornadas em cola alto relevo na cor vermelha, como demonstrado na figura 1.

Figura 1. Representação do Todo

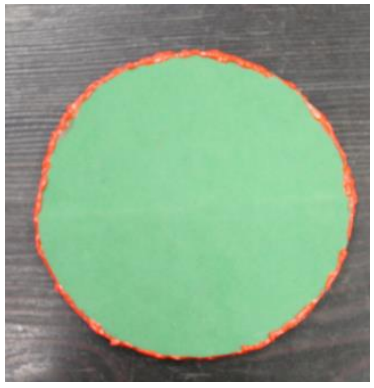

Fonte: Elaborada pelos autores.

Além disso, nas determinações da BNCC para o desenvolvimento das habilidades previstas, está descrita a necessidade de levar em consideração as experiências vivenciadas pelos alunos, conectando o seu cotidiano aos objetos. Por isso, pensamos na 


\section{ENSIN@UFMS 2021}

ISSN 2525-7056

elaboração de uma situação problema, para desenvolver o conceito de fração, como representado a seguir:

Uma pizza em formato de um círculo foi dividida em 8 partes. José comeu 3 pedaços e seu irmão João comeu 2 pedaços. Introduzindo assim o número fracionário, como no modelo abaixo, na representação dos números $\frac{3}{8} \mathrm{e} \frac{2}{8}$.

A partir dessa situação problema e usando o material manipulável, representado na figura 1 é possível explicar ao estudante cego como representar a fração, como exemplificado na figura 2 :

Figura 2. Representação de fração
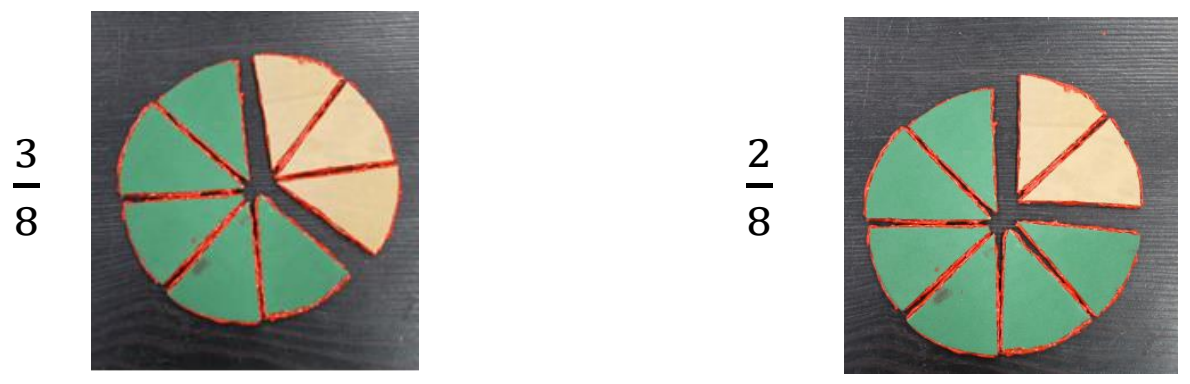

Fonte: Elaborada pelos autores.

No caso dos estudantes cegos é preciso que as práticas em sala de aula sejam adaptadas, e uma possibilidade é usar materiais manipuláveis e situações desafiadoras, sendo muito importante, além do modelo concreto, os estímulos por meio de práticas pedagógicas desafiadoras na forma de problemas do cotidiano, favorecendo o estímulo e a curiosidade. De acordo com Schoenfeld (1992), o conhecimento matemático é sobretudo proveniente da vida em sociedade, ou seja, das interações sociais. Por isso, a mediação do professor e os múltiplos estímulos, por meio de situações problemas, podem direcionar e facilitar o aprendizado, promovendo o desenvolvimento de competências e habilidades determinantes para a construção do conhecimento matemático.

Segundo Lupinacci e Botin (2004) a resolução de problemas é um método bastante eficaz a ser utilizado pelo professor para desenvolver o raciocínio e para motivar os alunos para o estudo da Matemática, desafiando-os através da exploração de situações problemas. Além da utilização de modelos concretos, é preciso que o professor de matemática na sala de aula consiga estimular o comprometimento dos alunos ao 


\section{ENSIN@UFMS 2021}

ISSN 2525-7056

aprendizado da matemática, trabalhando com uma temática voltada a resolução de problemas e ao universo dos alunos como exemplificamos na proposta a seguir:

Uma pizza média foi dividida em 8 pedaços. João comeu 2 pedaços e José comeu 3 pedaços, e guardou a parte que faltava para seus pais. Sabendo que a embalagem informava que o peso líquido da pizza é de $400 \mathrm{~g}$, determine os seguintes dados:

a) A fração que representa a parte de João

b) A fração que representa a parte de José

c) A fração que representa a parte de seus país.

d) A quantidade em gramas de cada pedaço

e) A quantidade em gramas que os dois comeram juntos.

Essa atividade traz um exemplo de problema que pode ser utilizado para a introdução de adição de fração, no sentido de desafiar e estimular o estudante, fazendo com que ele utilize os conhecimentos previamente construídos para realizar esta atividade. A aplicação dessa atividade começa com a leitura da situação problema junto com a turma, nessa parte da atividade a função que cabe ao professor é de contribuir com a interpretação do texto, deixando para a turma a Identificação, a investigação e o planejamento para possibilitar a resolução da situação problema, ou seja, fazer com os alunos reconheçam especificamente o que se precisa resolver e como isso será feito, analisando e investigando a melhor forma de chegar à resolução do problema.

Quando pensamos no público em questão, estudantes com cegueira, é de extrema importância a adaptação, por isso a proposta desse relato de experiencia é criar condições para a introdução das frações e das operações de adição e subtração de frações com o mesmo denominador, conforma exemplificado na figura 3.

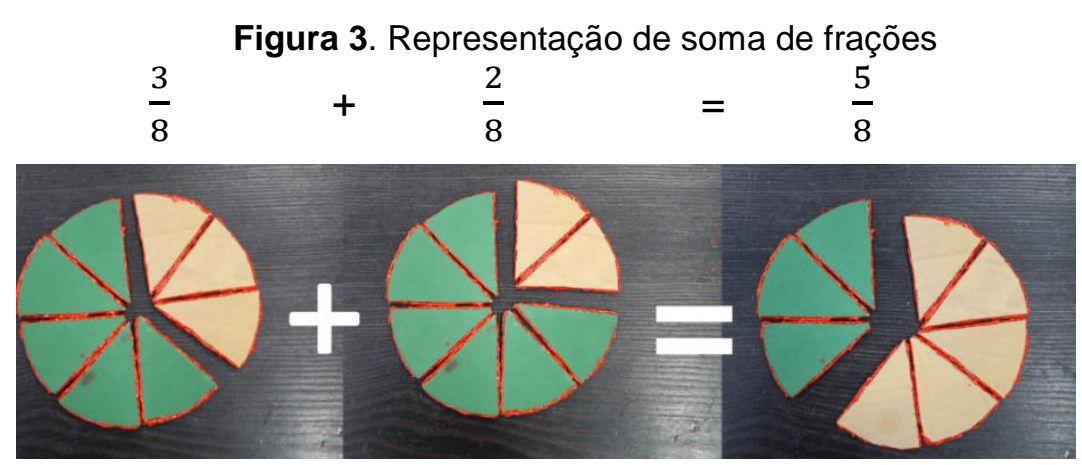

Fonte: Elaborado pelos autores. 
Além de ser possível com o mesmo modelo concreto trabalhar com o conceito de frações equivalentes, como da figura 4, é preciso na construção do conceito de fração mostrar ao estudante diversas possibilidades, como dividir a figura geométrica em diferentes partes iguais.

Figura 4. Equivalência de fração

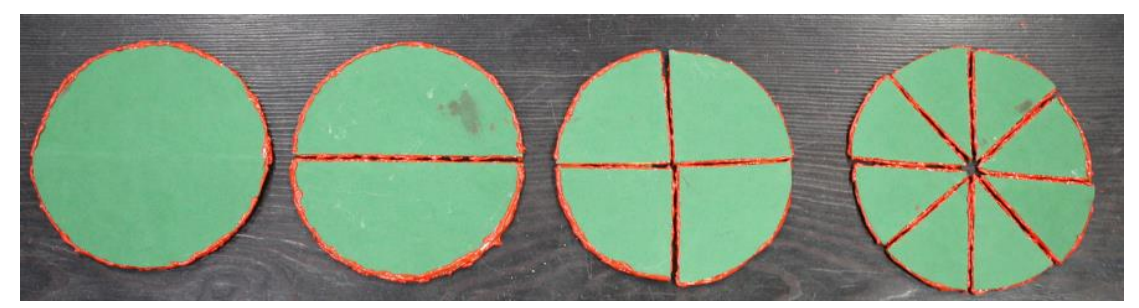

Fonte: Elaborado pelos autores.

Sabemos que é de extrema importância a abordagem utilizando situações problemas, por isso para dar continuidade ao processo de ensino e aprendizagem de fração propomos a resolução de outra situação problema:

$\mathrm{Na}$ caixa da pizza informava que o peso líquido era de $400 \mathrm{~g}$. José e Paulo decidiram comprar duas caixas de pizza, sendo uma no sabor muçarela e outra no sabor calabresa. Ao chegar em casa os irmãos José e Paulo partiram a pizza de muçarela em 4 pedaços. Já a pizza de calabresa foi partida em oito pedaços por seus pais.

Sabendo que João comeu um pedaço de muçarela e seu pai comeu 2 de calabresa. Quantas gramas cada um comeu?

Na primeira parte da construção, pede-se ao estudante para dividir $400 \mathrm{~g}$ pelo valor total de fatias, para que se conheça o valor em gramas de cada parte. Após essa indagação, é possível fazer com que o estudante entenda que a fração que João comeu é igual a de seu pai, pois pelo princípio da equivalência de frações $\frac{1}{4}=\frac{2}{8}$, e no nosso caso concreto fazer o aluno observar que $\frac{1}{4}$ da pizza tem a massa de 100 gramas. E $\frac{2}{8}$ da outra pizza também tem a massa de 100 gramas.

Umas das determinações da BNCC é a elaboração de problemas por parte dos alunos. Assim, as atividades de resolução de problemas propostas podem contribuir para que os alunos formulem novos problemas baseando-se na reflexão e no questionamento do que foi visto em sala de aula, desenvolvendo a capacidade de abstração, que segundo 


\section{ENSIN@UFMS 2021}

ISSN 2525-7056

a BNCC são decorrentes das atividades de elaborar e questionar situações cotidianas (BRASIL, 2018).

Com base nas determinações da BNCC para o desenvolvimento processual do estudo das frações, é possível pedir aos estudantes para que elaborem exemplos ou situações problemas que apresentem as frações das pizzas que tenham a mesma massa, ou seja, encontre frações equivalentes.

Portanto, logo após a explicação de que frações diferentes podem representar a mesma massa de pizza, o próximo passo é o estudo do conceito de equivalência de fração, por meio de modelo concreto, como exemplificado na figura 5, utilizando os estímulos remanescentes do aluno cego para abordar o conceito de equivalência de fração.

Neste caso, podemos pedir para que o aluno cego represente as frações com o uso de materiais manipuláveis, que foram confeccionadas com texturas e cores diferentes, papeis com texturas diferentes para estudantes cegos, representados por verde e rosa para estudantes videntes.

Figura 5. Frações Equivalentes

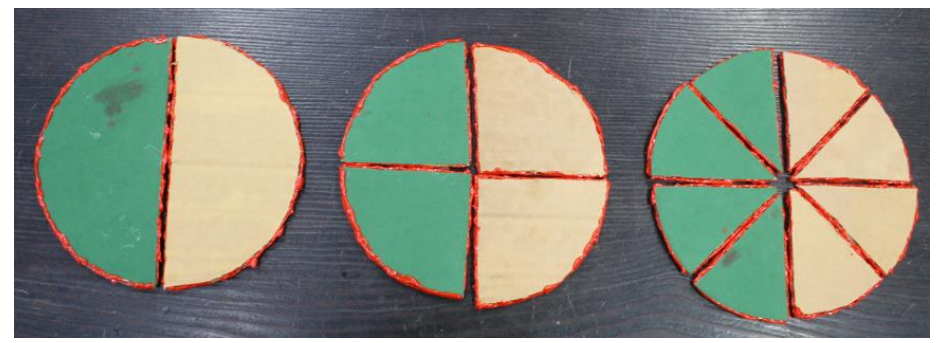

Fonte: Elaborado pelos autores.

Nesse relato de experiência apresentamos uma possibilidade de adaptação curricular para o ensino de fração para os aluno cegos, abordando os conceitos iniciais de fração, as operações de frações com o mesmo denominador e as equivalências de frações utilizando o modelo concreto já abordado, mas existe uma grande limitação nas operações de frações com os denominadores diferentes devido à complexidade dos cálculos e operacionalização dos múltiplos comuns para os alunos cegos, sendo assim, a continuação da proposta dessa prática é a apresentação do multiplano, representado na figura 6, o qual pode facilitar nos cálculos de soma e subtração. 
Figura 6. Multiplano

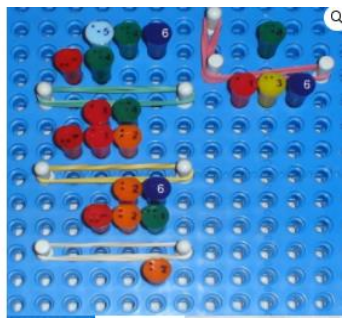

Fonte: MULTIPLANO (2021).

O Multiplano, segundo o seu criador, Professor Rubens Ferronato, é um aparelho didático destinado a auxiliar o aprendizado da matemática e estatística, e é constituído por um tabuleiro retangular operacional no qual são encaixados pinos, elásticos e hastes onde podem ser combinadas duas ou mais peças podendo representar um objeto ou operação matemática que se pretenda aprender e compreender por meio do tato (MULTIPLANO, 2021).

No multiplano o professor pode representar as frações texturizadas (representada na cor verde para videntes) da figura 5. Assim como na representação de fração em linguagem e códigos matemáticos, a parte superior representa o numerador e a parte inferior representa o denominador, como representada na figura 7. E, a explicação parte do princípio da simplificação de fração, e nesse caso, é preciso fazer o aluno entender que ao dividir tanto o numerador e quanto o denominador por 2 da primeira para segunda fração, e da segunda para a terceira, a relação de equivalência não se altera.

Figura 7. Frações equivalentes no Multiplano

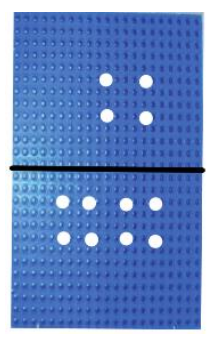

$\frac{4}{8}$

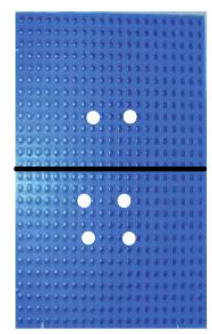

$\frac{2}{4}$

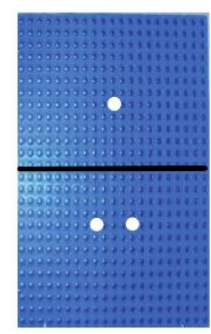

$\frac{1}{2}$

Fonte: Elaborado pelos autores.

Logo após a apresentação das frações, e a explicação da equivalência de frações no multiplano, é importante pedir ao estudante com DV que descubra outras frações 
equivalentes, como exemplificado na figura 8. É fundamental que o aluno tente descobrir as frações sozinho, para que compreenda o conceito.

Figura 8. Atividade de frações equivalentes
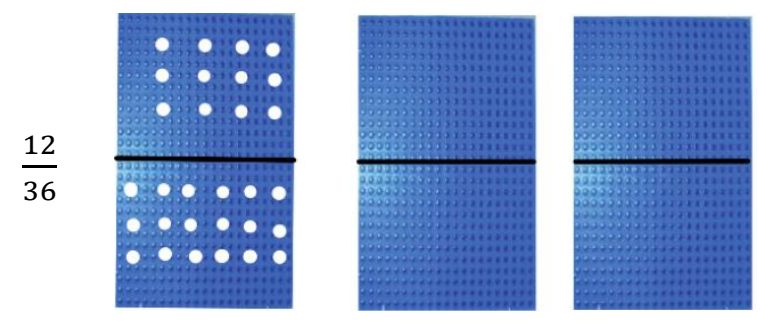

Fonte: Elaborado pelos autores.

Os estudantes precisam entender que as frações, além da possibilidade de serem representadas como uma parte, também são representações de um número, e como todos os conjuntos numéricos é preciso entender a relação de ordenação pois, segundo Bertoni (2008) o objetivo do ensino das frações na sala de aula, além de designar e representar à noção de número fracionário, com os quais se poderá operar, também pode ser comparada com os números naturais, podendo ser representada na reta numérica.

Antes de trabalhar a reta numérica é preciso que os estudantes entendam a relação entre duas frações, e utilizando as frações já trabalhadas é possível fazer a relação de uma forma que o aluno utilize o conhecimento já construído, ou seja, partindo do conhecimento que o estudante já tem.

Figura 9. Relação entre duas frações com o mesmo denominador

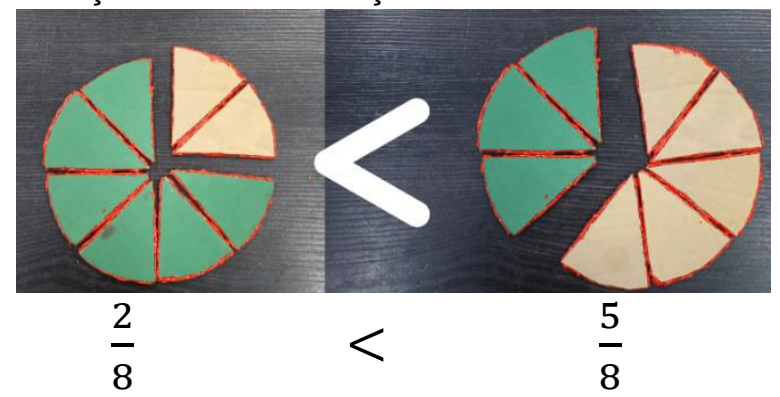

Fonte: Elaborado pelos autores.

Após o entendimento das relações de ordens entre frações, pode-se introduzir a reta numérica. Para a adaptação pode-se utilizar um barbante com os números escritos em braile e na forma de algarismo sendo representados por botões, e tendo uma estrutura em forma de um seta nas extremidades para representar a continuidade da reta numérica, 


\section{ENSIN@UFMS 2021}

ISSN 2525-7056

tornando possível realizar a atividade utilizando o tato, e possibilitando a acessibilidade a um dos objetos do conhecimento de matemática pelo estudante cego, pois como explica Lopes (2017) as atividades devem ser planejadas a partir das necessidades e especificidades do estudante. O uso desse recurso manipulável da reta numérica construída com barbante e botões beneficia também a aprendizagem de estudantes videntes, que conseguem visualizar um conceito, muitas vezes trabalhado somente de maneira abstrata.

A partir do processo de ordenação dos racionas e da explicação da existência de números entre o zero e um, entre o um e o dois e entres o dois e o três, e que esses números racionais podem ser escritos na forma de fração, portanto um exemplo para essa proposta é que o professor solicite para que o estudante determine a ordenação das frações $\frac{2}{8}, \frac{5}{8}$ e $\frac{12}{8}$, com o auxílio da reta numérica, representada na figura 10 .

Figura 10. Ordenação na reta numérica

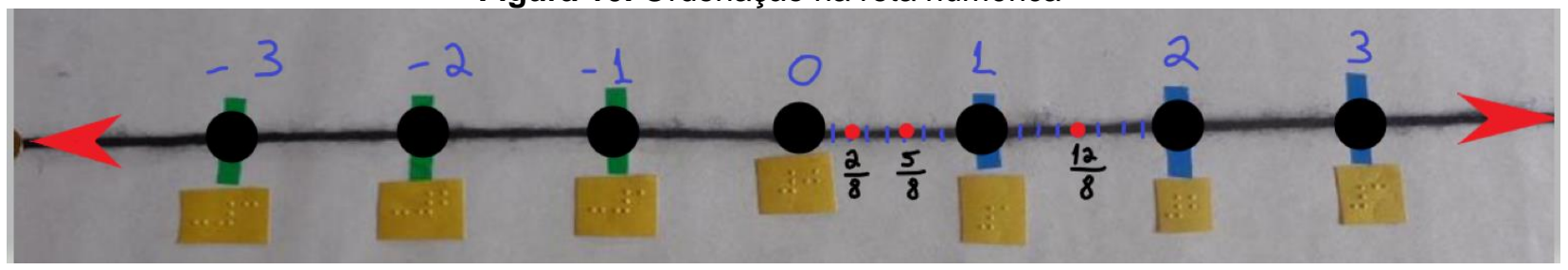

Fonte: Elaborado pelos autores.

Até este momento, sugerimos que a construção dos números fracionários em relação as operações, equivalência e a representação destes na reta numérica, sejam realizadas com os denominadores iguais. Para realizar as operações de frações com denominadores diferentes, sugerimos o auxílio do multiplano, como exemplificado na figura 11 , pedindo que o estudante cego determine qual é a maior fração.

Nessa proposta trabalhamos com as frações $\frac{\mathbf{4}}{\mathbf{5}}$ e $\frac{\mathbf{3}}{\mathbf{4}}$, que serão representadas no multiplano, e utilizando o conceito de fração equivalente, estimulando o uso do material manipulável, encontra-se um múltiplo comum aos denominadores.

Para que o aluno realize o cálculo dos Múltiplos de 5 e 4 respectivamente, ele pode pontuar os múltiplos de cada número isoladamente, sinalizando aqueles que são comuns:

$$
\begin{gathered}
M(5)=\{0,5,10,15, \mathbf{2 0}, 25,30,35, \mathbf{4 0}, 45,50,55,60 \ldots\} \\
M(4)=\{0,4,8,12,16,20,24,28,32,36,40,44,48,52,56,60 \ldots\}
\end{gathered}
$$




\section{ENSIN@UFMS 2021}

ISSN 2525-7056

A escolha da técnica descrita para calcular os múltiplos entre dois números, se justifica por consideramos que ela seja mais fácil de operacionalizar com os alunos cegos, e pelo fato de ser uma mediação aberta, o estudante pode encontrar diferentes múltiplos, logo é preciso conversar e pedir que ele trabalhe sempre com o menor múltiplo possível, que nesse caso é o 20.

Figura 11. Comparação de Frações.

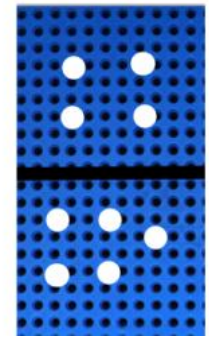

$\frac{4}{5}$

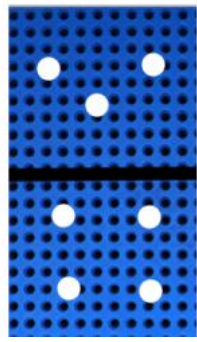

$\frac{3}{4}$

Fonte: Elaborado pelos autores.

Logo, as novas frações têm como denominador o número 20. Como observado na figura 12 .

Figura 12. Cálculo do novo denominador
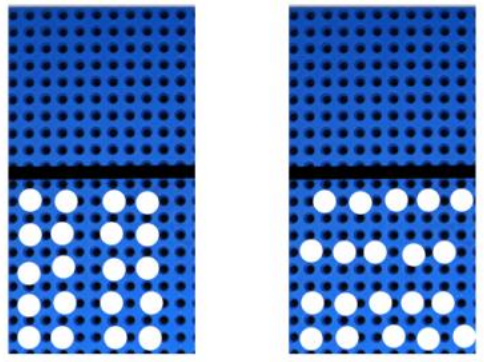

Fonte: Elaborado pelos autores.

O interessante de se trabalhar seguindo esta proposta é a manipulação das quantidades de pinos que representam os números, fazendo com que o estudante tente desenvolver a ideia de uma forma mais dinâmica, tocando nas peças e trabalhando a proporcionalidade. O primeiro questionamento a ser feito aos estudantes é: Qual será o processo para transformar essas frações?

Para uma melhor visualização e entendimento da relação de frações é preciso transformar as duas em frações equivalentes e com o mesmo denominador, que nesse caso, pelo cálculo do menor múltiplo comum é o 20. 


\section{ENSIN@UFMS 2021}

ISSN 2525-7056

Nessa proposta de material manipulável é possível que o estudante se envolva mais com a operação e entenda melhor o que precisa ser feito para descobrir uma fração equivalente à $\frac{3}{4}$ com denominador igual a 20. Para isso é preciso explicar com apoio do material manipulável que ele precisa multiplicar o denominador por 5 e para manter a equivalência da fração também tem que multiplicar o numerador por 5 encontrando a nova fração $\frac{15}{20}$, processo representado na figura 13 .

Utilizando pensamento e processos análogos ao cálculo de uma fração equivalente à $\frac{3}{4}$, realizados na figura 13 , parte-se agora para determinar a fração equivalente à $\frac{4}{5}$, que já se sabe que o denominador é 20, sendo necessário multiplicar tanto o denominador e numerador por 4 . Dessa forma determinando a fração $\frac{16}{20}$ que é equivalente à $\frac{4}{5}$, como demonstramos na figura 14 .

Figura 13. Cálculo de uma Fração equivalente à $\frac{3}{4}$
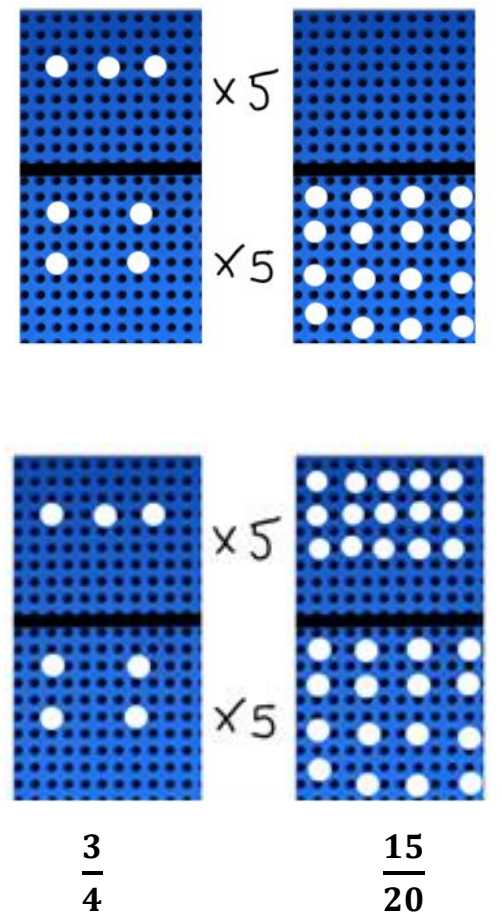

Fonte: Elaborado pelos autores. 
Figura 14. Fração Equivalente a $\frac{4}{5}$

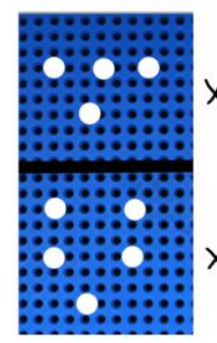

$\frac{4}{5}$

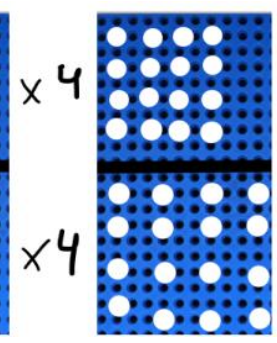

$\frac{16}{20}$

Fonte: Elaborado pelos autores.

Depois de fazer o cálculo para encontrar as frações equivalentes a $\frac{4}{5}$ e $\frac{3}{4}$, que são respectivamente $\frac{16}{20} \mathrm{e} \frac{\mathbf{1 5}}{\mathbf{2 0}}$, sendo possível assim ordenar as frações.

Construindo processualmente a adaptação para o ensino dos números fracionários, iniciando com a representação das frações como parte de um todo e partindo para a introdução do conceito de equivalência de fração e as operações de frações com o mesmo denominador, chegamos ao final do modelo de proposta de adaptação curricular para o ensino de fração, que tem como grande objetivo a adaptação das operações de adição entre frações com denominadores diferentes para estudantes cegos, no intuito de construção de uma prática pedagógica que facilite o aprendizado das operações de somar e subtrair dos números fracionários, organizada em etapas, o que contribui para a aprendizagem do estudante e com o acompanhamento do processo de ensino e aprendizagem do professor, que consegue identificar as dificuldades do estudantes e as necessidades de intervenção no processo.

Segundo Brawand e Johnson (2016) o desenvolvimento de objetos ou ferramentas pedagógicas para o público com DV necessita de mais pesquisas, estratégias e materiais didáticos, pois o desenvolvimento desses materiais concretos e manipuláveis deve oferecer aos estudantes com deficiência visual outros meios de estímulos.

Por isso, propomos a adaptação utilizando o multiplano para a soma das frações $\frac{2}{6}$ $+\frac{3}{4}$, representada na figura 15 
Figura 15. Soma de Fração
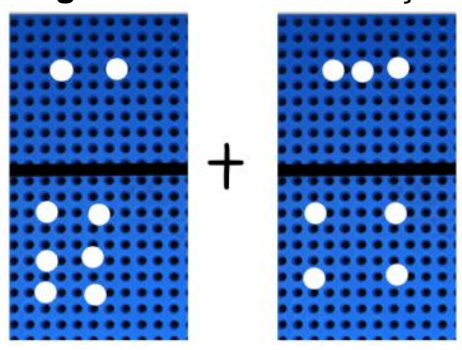

$$
\frac{2}{6}+\frac{3}{4}
$$

Fonte: Elaborado pelos autores.

Para que o estudante resolva o desafio proposto é preciso que ele compreenda que para facilitar os cálculos seria melhor que as frações tivessem o mesmo denominador, então, é preciso transformá-las em frações equivalentes, e para isso é necessário determinar um múltiplo comum ao 6 e 4 . Sabendo que o estudante pode trabalhar com qualquer múltiplo comum como 12, 24 e 36, ou seja, são infinitos. Porém, é importante orientar, conversando e explicando que a utilização dos números menores vai facilitar a operação, por isso escolhe-se o mínimo múltiplo comum (M.M.C), no caso o 12.

A prática pedagógica mais comum para ensino de cálculo de frações é o uso do M.M.C, no entanto acreditamos que nesse momento não seja interessante fixar mais uma regra para as operações de frações, pois o estudante cego ainda está aprendendo a manusear um novo material, então propomos que esse conteúdo seja trabalhado em momento posterior, após o domínio do multiplano.

Por isso pode-se trabalhar, a princípio com os cálculos dos múltiplos comuns dos denominadores 6 e 4, é possível determinar as frações equivalentes para cada uma das frações. No caso de $\frac{2}{6}$, como o denominador é 12 , tem que multiplicar tanto o numerador e denominador por 2 e no caso de $\frac{3}{4}$, multiplicar o numerador e denominador por 3. 


\section{ENSIN@UFMS 2021}

ISSN 2525-7056

Figura 16. Cálculo de frações equivalentes

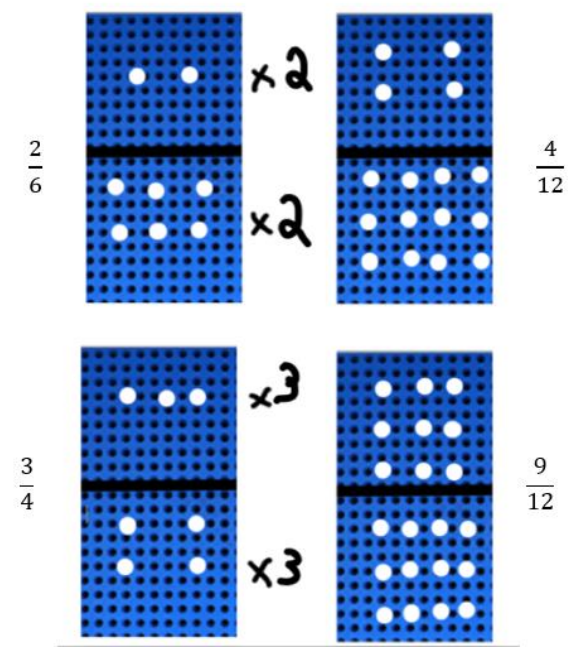

Fonte: Elaborado pelos autores.

Após a determinação das frações equivalentes para cada fração, calcula-se e a soma como exemplificado na figura 17.

Figura 17. Soma de Fração

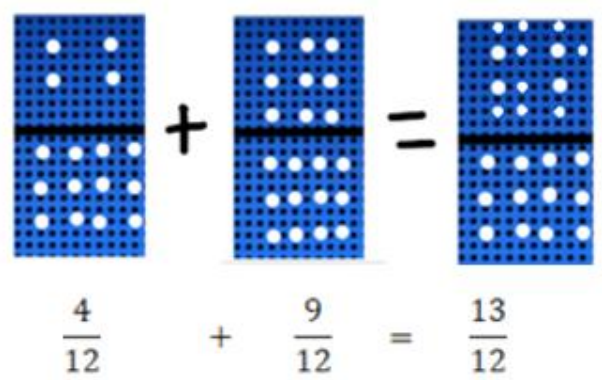

Fonte: Elaborado pelos autores.

Assim, para chegar ao resultado o estudante deve manter os denominadores e somar os numeradores.

É imprescindível que o estudante cego tenha variadas possibilidades de realização de resolução de situações problemas, explorando o multiplano e assim apreendendo o conteúdo previsto para seu ano escolar. Adaptações curriculares como esta podem garantir a permanência desses estudantes na educação básica, possibilitando que vivenciem uma prática de educação inclusiva, aprendendo junto com os outros estudantes da turma. 


\section{ENSIN@UFMS 2021}

ISSN 2525-7056

\section{Considerações Finais}

Neste relato descrevemos uma possibilidade de adaptação curricular para ensino de operações com frações para estudantes com cegueira. O ensino de matemática está previsto nos documentos que orientam a educação básica, e é considerado relevante no processo de ensino e aprendizagem, sendo conteúdo base para outras áreas de conhecimento, porém a matemática é considerada por muitos como um conhecimento difícil e desafiador, tanto para os professores ensinarem quanto para os estudantes aprenderem, e por isso estudos apontam a importância da matemática ser ensinada de maneira contextualizada, sendo desafiadora e estimulante, para que os estudantes se interessem, aprendam e a utilizem em sua rotina, como na proposta de ensino por meio de situações problemas, opção desta proposta de adaptação curricular, que deve ser estendida também aos estudantes PAEE.

Vivemos em um contexto de diversidade, no qual compreendemos que apesar das diferenças, todos devem ter, na perspectiva dos direitos humanos, direitos iguais, dentre eles o direito à educação. O paradigma da educação inclusiva defende esse direito organizando políticas públicas e ações que contribuem com o acesso e permanência de todos na escola, dentre eles a pessoa PAEE, dentre as quais está a pessoa cega.

Assim, soma-se aos desafios comuns ao ensino da matemática ensinar estudantes com cegueira (DV), os quais precisam que o processo de ensino e aprendizagem explorem seus outros sentidos e oportunizem acesso aos conteúdos previstos e o consequente sucesso escolar.

Considerando as características comuns às pessoas cegas, estudos e pesquisas sobre ensino de matemática e ensino de matemática para pessoas com DV e tentando responder a inquietação "Como ensinar fração para estudantes cegos?" desenvolvemos a sequência de atividades apresentada, explorando recursos táteis e explicação detalhada, passo a passo, para que o estudante em questão compreenda o raciocínio exigido para realizar operações com frações, e não apenas memorize sequência de cálculos.

A adaptação curricular relatada foi embasada nas leituras e reflexões realizadas nos encontros da atividade de extensão e contou com a troca de ideias de todos os integrantes do grupo, e com a orientação individual da coordenadora do projeto, até chegarmos à versão apresentada, a qual foi desenvolvida com a contribuição de todos os integrantes do projeto de extensão, incluindo a professora do projeto, que é coautora na escrita do 
presente relato de experiência. Essa troca de informações, leituras e experiências entre diferentes pessoas, professores que atuam na educação básica, estudantes de graduação em pedagogia e licenciaturas e profissionais que atuam com pessoas PAEE foi de extrema relevância para o desenvolvimento desta proposta, possibilitando ampliar o olhar para diferentes aspectos, especificidades e possibilidades, logo destacamos a necessidade de que isso aconteça também no contexto escolar, que os professores possam realizar essas trocas para embasarem suas práticas e adaptações curriculares.

O uso de recursos diferentes de lousa e caderno é fundamental na adaptação curricular, e a proposta descrita, com uso de materiais manipuláveis, multiplano e representação da reta numérica, pode ser viabilizada com recursos de baixo custo, mas com grande impacto no processo de ensino e aprendizagem, o que oportuniza ao estudante cego acessar e permanecer na escola, avançando nos anos escolares.

Trata-se de uma possibilidade, dentre tantas possíveis, mas que pode inspirar, embasar e servir como ponto de partida para outras práticas de adaptação curricular para estudantes com cegueira, pois sem adaptação curricular, nós professores não estamos desempenhando nosso papel na educação, garantir a todos experiências de aprendizagem, inclusão escolar e educação de qualidade.

A partir deste relato concluímos que é possível ensinar matemática para estudantes com DV na educação básica, mas isso requer revisão de práticas docentes e adaptação curricular.

\section{Referências}

BERTONI, N. E. A construção do conhecimento sobre número fracionário. Boletim de Educação Matemática, v. 21, n. 31, p. 209-237, 2008. Disponível em: https://www.periodicos.rc.biblioteca.unesp.br/index.php/bolema/article/view/2111. Acesso em: 8 jul. 2021.

BRASIL. Ministério da Educação. Base Nacional Comum Curricular. Brasília, 2018. Disponível em: http://basenacionalcomum.mec.gov.br. Acesso em: 8 jul. 2021.

BRASIL, Lei Brasileira de Inclusão no 13.146 de 2015. Disponível em: http://www.planalto.gov.br/ccivil_03/_ato2015-2018/2015/lei/l13146.htm. Acesso em: 8 jul. 2021.

BRASIL, Política Nacional de Educação Especial na Perspectiva da Educação Inclusiva de 2008. Disponível em: portal.mec.gov.br/seesp/arquivos/pdf/politica.pdf Acesso em: 8 jul. 2021. 
BRASIL, Programa de Capacitação de Recursos Humanos do Ensino Fundamental: deficiência visual vol. 1 fascículos I - II - III / Marilda Moraes Garcia Bruno, Maria Glória Batista da Mota, colaboração: Instituto Benjamin Constant. Ministério da Educação, Secretaria de Educação Especial, 2001. Disponível em: http://portal.mec.gov.br/seesp/arquivos/pdf/def_visual_1.pdf. Acesso em: 8 jul. 2021.

BRASIL, Lei de Diretrizes e Bases da Educação Nacional (LDBEN) no 9394de 1996. Disponível em: http://portal.mec.gov.br. Acesso em: 8 jul. 2021.

BRAWAND, A; JOHNSON, N. Effective methods for delivering mathematics instruction to students with visual impairments. Journal of Blindness Innovation and Research. National Federation of the Blind. v. 6, n. 1, 2016. Disponível em: https://nfb.org/images/nfb/publications/jbir/jbir16/jbir060101abs.html. Acesso em: 8 jul. 2021.

JANUZZI, G. S. M. A educação do deficiente no Brasil: dos primórdios ao início do século XXI. Campinas, São Paulo: Autores associados, 2004.

LOPES, S. Adaptação Curricular: O Que É? Por Quê? Para Quem? E Como Fazê-La? Educação Básica Revista, vol.3, n.1, p.1-27, 2017.

LUPINACCI, M. L. V; BOTIN, M. L. M. Resolução de problemas no ensino de matemática. In: Anais do VIII Encontro Nacional de Educação Matemática, Recife, p. 1-5, 2004. Disponível em: http://www.sbembrasil.org.br/files/viii/pdf/02/MC18361331034.pdf. Acesso em: 8 jul. 2021.

MAZZOTTA, M. J. S. Educação Especial no Brasil - História e Políticas Públicas. 5. Ed. São Paulo: Editora Cortez, 2005.

MOLLOSSI, L. F. S. B. Educação Matemática no Ensino Fundamental: Um Estudo de Caso com Estudante Cego. 2013.Trabalho de Conclusão de Curso (Curso de Licenciatura em Matemática). Universidade do Estado de Santa Catarina, Joinville, 2013. Disponível em: https://sistemabu.udesc.br/pergamumweb/vinculos/00001a/00001ad9.pdf. Acesso em: 8 jul. 2021.

MULTIPLANO. Multiplano: quem somos. Disponível em:

http://multiplano.com.br/multiplano-quem-somos . Acesso em: 8 jul. 2021.

NUNES, T; BRYANT, P. Understanding rational numbers and intensive quantities, Paper 3: Understanding rational numbers and intensive quantities. University of Oxford. 2007.

UBER, A. O ensino da matemática para o educando cego. In: V Congresso Brasileiro Multidisciplinar de Educação Especial. Londrina, PR, 2009. p 2960- 2970. Disponível em:

http://www.uel.br/eventos/congressomultidisciplinar/pages/arquivos/anais/2009/355.pdf. Acesso em: 8 jul. 2021. 
SARACHO, O. N. An integrated play-based curriculum for young children, 1. Ed. Routledge, 2020.

SCHOENFELD, A. H. Learning to think mathematically: Problem solving, metacognition, and sense making in mathematics. In: D. Grouws (Ed.), Handbook for Research on Mathematics Teaching and Learning, p. 334-370. New York: MacMillan, 1992.

SCRUGGS, T. E.; MASTROPIERI, M. A.; BERKELEY S.; GRAETZJ. E. Do special education interventions improve learning of secondary content? A meta-

analysis. Remedial and Special Education, v. 31, n. 6, p. 437-449, 2010. Disponível em: https://eric.ed.gov/?id=EJ904253. Acesso em: 8 jul. de 2021.

\section{NOTAS}

\section{IDENTIFICAÇ̃̃O DE AUTORIA}

Gilbson José Velasco Souza Filho. Mestrando No Programa de Mestrado Profissional em Matemática em Rede Nacional (Profmat). Universidade Federal da Bahia, Departamento de Matemática, Salvador, BA, Brasil. E-mail: meuprofessordeexatas@gmail.com

(D) https://orcid.org/0000-0001-7875-9525

Regiane da Silva Barbosa. Doutora em Educação Especial. Professora Adjunta da Universidade Federal da Bahia, Faculdade de Educação/ Departamento I, Salvador, BA, Brasil.

E-mail: regiane.barbosa@ufba.br

(i) https://orcid.org/0000-0002-0305-902X

\section{AGRADECIMENTOS}

Não se aplica.

\section{FINANCIAMENTO}

Não se aplica.

\section{CONSENTIMENTO DE USO DE IMAGEM}

Não se aplica.

\section{APROVAÇÃO DE COMITÊ DE ÉTICA EM PESQUISA}

Não se aplica.

\section{LICENÇA DE USO}

Autores mantêm os direitos autorais e concedem à revista ENSIN@ UFMS - ISSN 2525-7056 o direito de primeira publicação, com o trabalho simultaneamente licenciado sob a Licença Creative Commons Attribution (CC BY-NC-SA 4.0), que permite compartilhar e adaptar o trabalho, para fins não comerciais, reconhecendo a autoria do texto e publicação inicial neste periódico, desde que adotem a mesma licença, compartilhar igual.

\section{EDITORES}

Patricia Helena Mirandola Garcia, Eugenia Brunilda Opazo Uribe, Gerson dos Santos Farias.

\section{HISTÓRICO}

Recebido em: 19/07/2021 - Aprovado em: 10/11/2021 - Publicado em: 06/12/2021.

\section{COMO CITAR}

SOUZA FILHO, G. J. V; BARBOSA, R. S. Ensino de Operações de Frações para Estudantes Cegos: Uma Possibilidade de Adaptação Curricular. Revista ENSIN@ UFMS, Três Lagoas, v. 2, n. 6, p. 133-155. 2021. 